Caso para Ensino

\section{Fique em Casa, a Casa Porto Entrega: Empreendedorismo Humanizado na Pandemia}

\author{
Stay at Home, Casa Porto Delivers: Humanized Entrepreneurship during \\ Pandemic
}

Disciplina: Empreendedorismo, Gestáo de Pessoas

Temática: Empreendedorismo Humanizado

Setor de atividade: Serviços, Alimentaçáo

Regiáo: Rio de Janeiro/Brasil
Valéria Quiroga Vinhas' ${ }^{10}$ Ana Luiza Szuchmacher V. Lopes ${ }^{2}$

\title{
INTRODUÇÃO
}

No dia 8 de abril de 2020, o primeiro boletim atualizado sobre o coronavírus, divulgado pela Secretaria de Estado de Saúde do Rio de Janeiro, informava que o estado acumulava 1.688 casos confirmados de COVID-19 e 92 óbitos ${ }^{1}$.

Enquanto ajudava na organização das entregas em domicílio (serviço de delivery) das refeiçóes da Casa Porto, Raphael Vidal comentou rapidamente esses números com alguns membros de sua equipe de cozinha e salão. Haviam aderido ao sistema de entrega por aplicativos no dia 18 de março de 2020.

Encerradas as atividades do dia, tomou sua última cerveja daquela tarde com a equipe de funcionários e foi

1. Universidade Federal do Rio de Janeiro, Instituto COPPEAD de Administração, Rio de Janeiro, RJ, Brasil. 2. Universidade Federal do Estado do Rio de Janeiro, Departamento de Estratégia de Gestão, Rio de Janeiro, RJ, Brasil.

Como citar: Vinhas, V. Q., \& Lopes, A. L. S. V. (2021). Fique em casa, a Casa Porto entrega: Empreendedorismo humanizado na pandemia. Revista de Administração Contemporânea, 25(spe), e200253. https://doi.org/10.1590/1982-7849rac2021200253.por para casa. A pé mesmo, afinal, desde 2008 morava ali ao lado, no Morro da Conceição.

Pensativo, Raphael estava preocupado com a situação da Casa Porto. Aquela semana seria a última em que o Pendura Invertido estaria ativo. Tratava-se de projeto idealizado por ele para ajudar com as receitas da Casa Porto baseado no adiantamento de pagamentos por parte dos clientes, para usufruto das compras assim que a pandemia passasse. O slogan era "Pendura Invertido. Nossa hora de pendurar com vocês". A estratégia de adiantamento de pagamentos incluía também a venda de ingressos para futuros eventos da Casa Porto, como o baile de espuma à fantasia agendado para 31 de outubro de 2020, data em que Raphael imaginava que a situação de pandemia já estaria contornada.

Classificação JEL: A20, O15, L66 Editor-chefe: Wesley Mendes-Da-Silva (Fundação Getulio Vargas, EAESP, Brasil) 둥 Editora Associada: Paula C. P. de S. Chimenti (Universidade Federal do Rio de Janeiro, COPPEAD, Brasil) Editor Convidado: Leonardo Marques (Universidade Federal do Rio de Janeiro, COPPEAD, Brasil) (1) Pareceristas: Mariana Euflausino (Universidade Estadual de Maringá, DAD, Brasil) (C) Cristiane Gontijo Araújo (Universidade Federal de Minas Gerais, Brasil)

Relatório de Revisão por Pares: A disponibilização do Relatório de Revisão por Pares não foi autorizada pelos revisores. Recebido: $22 / 07 / 2020$ Última versão recebida em: 14/12/2020
Aceite em: 15/12/2020

\begin{tabular}{|c|c|c|c|c|c|c|c|c|c|}
\hline & 1 & 2 & 3 & 4 & 5 & 6 & 7 & 8 & 9 \\
\hline $1^{a}$ rodada & 9 & $\stackrel{9}{2}$ & & & & & & & \\
\hline $2^{a}$ rodada & 0 & & & & & & & & \\
\hline $3^{a}$ rodada & $\theta$ & & & & & & & & \\
\hline
\end{tabular}


No dia 14 de março de 2020 tomara a decisão de implantar um canal de distribuição baseado em entregas em domicílio por aplicativos como iFood e Uber Eats, além do uso de motoboys independentes apenas para bairros não atendidos pelos aplicativos. $\mathrm{O}$ serviço nunca havia sido oferecido pela Casa Porto, que até então funcionava somente com atendimento local. Assim que se confirmou a crise da pandemia, inúmeros estabelecimentos sentiram necessidade de desenhar alternativas de atendimento para fazer frente ao imperativo de "fechamento de portas".

No dia seguinte, o nome da Casa Porto se juntava ao de outros bares e restaurantes tradicionais em matéria veiculada pelo jornal $O G l o b o^{2}$, intitulada "Coronavírus: bares do Rio se reinventam para não fecharem as portas e agradar clientes", que registrava: "Já a Casa Porto, no Largo da Prainha, oferecerá uma dose de batida, pimenta e sobremesa por conta da casa para quem fizer pedidos pelo delivery. - Além das nossas minutas, vamos fazer entrega de comida de primeira necessidade. Se o cliente quiser uma quentinha de arroz, tem. Só de feijão, tem. Purê? Tem. Vamos atender a todos - explica Raphael Vidal.”

Com pouco tempo de uso dos aplicativos de entrega, Raphael já se ressentia do alto percentual que "perdia" em cima do valor de venda, o que impactava no seu faturamento mensal e, por consequência, na sua intençáo de manter o negócio em funcionamento e, principalmente, o salário de sua equipe de profissionais. E quando lia e refletia sobre as condiçóes precárias a que eram submetidos os entregadores dos aplicativos, incluindo jornadas de trabalho extenuantes, remuneração em queda, falta de proteçáo e segurança adequadas, seu incômodo aumentava ainda mais.

Diante de tantas incertezas, dificuldades e preocupaçóes, Raphael se perguntava como poderia manter seu negócio e o salário de seus funcionários no meio da crise causada pela pandemia do COVID-19. Como o serviço de delivery deveria ser configurado para que Raphael mantivesse a Casa Porto, paixão de sua vida, e o salário de seu quadro de funcionários, sem abrir máo dos aprendizados que recebera ao longo da vida, e que ditavam seu modo de ser empreendedor?

\section{COMO TUDO COMEÇOU}

Nascido na zona norte da cidade, de onde tirou inspiraçáo para parte do cardápio hoje oferecido na Casa Porto, Raphael saiu de casa aos 13 anos de idade para se afastar de um ambiente doméstico adverso e foi morar com os tios. Aos 16 anos, ingressou na Faculdade de Filosofia, situada no centro do Rio de Janeiro. Na tentativa de encontrar um meio para se sustentar e seguir seus dois grandes sonhos - conhecer pessoalmente escritores famosos e, um dia, tornar-se um deles -, passou a escrever o que chamou de "Cartas da existência". As cartas eram vendidas em envelopes para leitura em diferentes momentos do cotidiano, como no ônibus ou em casa antes de dormir.

Aos 18 anos, aproveitando o boom da internet dos anos 2000, idealizou e montou com alguns amigos uma revista de contos chamada Bagatelas, que reunia conteúdo de jovens escritores lusófonos. Intitulou-se o editor da revista e com seu esforço de divulgação (a partir de um fictício assessor de imprensa criado por ele mesmo), começou a ter seus contos divulgados em jornais de grande circulação e seu nome presente em pequenas notas nos jornais.

Munido de um portfólio de notas e recortes de jornal, Raphael decidiu entáo conversar com Marcelo, dono da livraria localizada dentro do Paço Imperial, cuja entrada há tempos era seu ponto de vendas das "Cartas da existência". Dividiu com ele sua ideia de promover uma roda de conversa com escritores, evento para o qual precisaria do espaço da Livraria Imperial. Com o aval de Marcelo, e com publicidade promovida pelos jornais, conseguiu executar seu primeiro evento de bate-papo com o escritor Sérgio Sant-Anna. O evento era informal e baseado em uma manhã e tarde de puro bate-papo e rodadas de cerveja. Com a lotaçáo máxima do espaço, a primeira edição do Encontros \& Bagatelas foi considerada um sucesso pelos participantes e organizadores.

Marcelo decidiu entáo apostar no potencial de Raphael e lhe propôs o emprego de administrador, com carteira assinada. Aquele espaço permitiu que Raphael passasse por uma frutífera experiência como empregado da livraria. Marcelo tratava todos com dignidade e respeito e mostrava o lado digno do trabalho. "Esse cara me ensinou como tratar o funcionário", declarou Raphael.

Entretanto, apesar das inúmeras iniciativas que ambos empreenderam juntos, a livraria não conseguiu manter-se funcionando. Raphael foi então indicado por Marcelo para um posto em uma grande livraria no Leblon. Porém, logo após um breve período de atuação, ele viu-se insatisfeito com o modo com que os funcionários eram tratados naquele local e começou a buscar oportunidades de trabalho como editor, conseguindo uma vaga na Editora Vieira \& Lent.

$\mathrm{Na}$ ocasião, Cilene Vieira admitiu Raphael mesmo sabendo que ele não detinha de fato nenhum conhecimento sobre o trabalho de ediçáo. Cilene se tornou, ao lado de Marcelo, o "segundo pilar de ética" e referência para o que Raphael afirmou fazer na Casa Porto.

Com esse emprego, e com pouco mais de 20 anos de idade, Raphael realizou o sonho de entrar no mercado editorial. Ali, Cilene Vieira ensinou tudo o que sabia para Raphael. Mais do que habilidades técnicas na área de edição, Cilene ensinou-o, pelo exemplo, que era possível ser eficiente e tratar os empregados com humanidade. 
Entretanto, por conta da crise econômica de 2008, aquela pequena editora de divulgação científica fechou suas portas, e Cilene teve que demitir Raphael, mas não sem antes, tal qual Marcelo, indicá-lo para um novo emprego. Foi assim que Raphael tornou-se coordenador editorial de uma editora de maior porte e mais conhecida. Empolgado no início, Raphael logo decepcionou-se com o modo como a gestão de pessoas era realizado. O contexto de insatisfaçáo com o ambiente de trabalho na nova editora levou então Raphael a decidir por montar o projeto de um festival literário no Morro da Conceição, inspirado nas rodas com escritores promovidas na Livraria Imperial: o Fim de Semana do Livro no Porto (FIM). Ele queria mostrar ao público que a intelectualidade residia nos livros e no que o escritor tinha de importante para transmitir: "como viver a vida".

Em 2012, o projeto FIM estava pronto, mas faltavam dinheiro e experiência para a execução. Com base em seu carisma e empenho, Raphael conseguiu, em pouco tempo, o patrocínio da prefeitura, a interlocuçấo com diversas editoras e o suporte financeirodaLight. Com dinheiro em mãos, acionou seus contatos e conseguiu o apoio de grandes nomes do ramo de assessoria de imprensa e produção cultural: Claudia Noronha e Bel Fernandes, respectivamente assessora de imprensa do MAM e produtor do Anima Mundi que, sem cobrar pelo serviço, apostaram no projeto. "Foi o último pilar de aprendizado profissional, de como lidar com uma relaçáo de empreendedorismo", nas palavras de Raphael. De um lado, Bel o ensinou tudo sobre produção, e de outro, Cláudia o tornou conhecido com a divulgação do FIM.

Sobrado alugado e transformado em cenário de botequim, escritores famosos (com nomes como Nei Lopes) convidados para bate-papos regados à cerveja, fornecedores e artistas da região divulgando o festival e exercendo seus trabalhos durante o evento: o FIM foi um sucesso.

No dia seguinte ao evento, Raphael recebeu uma proposta de trabalho como produtor cultural no Museu de Arte do Rio (MAR), que estava com inauguração prevista para 2013, ali na vizinhança da Praça Mauá. Ainda que fosse uma oportunidade jamais imaginada, Raphael continuava inquieto e sentindo que a FIM o havia mudado de maneira definitiva.

\section{A CASA PORTO}

Um dia, na saída do museu, sentado em um bar, se deparou com um vizinho que estava a caminho da imobiliária para devolver a Casarela - um sobrado que havia sido usado para promover festas e como depósito de bebidas vendidas no evento Escravos da Mauá. Ao saber da entrega do imóvel, Raphael alugou o local por $\mathrm{R} \$ 600,00$ e dali foi diretamente para o MAR negociar sua demissão. Com o dinheiro da rescisão, Raphael reformou o sobrado e, em paralelo, apresentou ao Porto Maravilha ${ }^{3}$ um projeto de abertura de centro cultural para capacitação de moradores da regiáo. Afinal, para a execução da FIM, ele havia mapeado pessoas que trabalhavam com culinária e que faziam cultura na região, mas que precisavam de capacitação para subir um degrau na vida profissional.

Assim nasceu a Casa Porto. Com o patrocínio mensal do Porto Maravilha, o centro cultural funcionava com oficina e cursos durante o dia e tinha apresentaçóes dos alunos à noite. Um ambiente ainda sem cozinha, onde vendia-se cerveja e realizavam-se atividades culturais (ver Anexo 1).

O projeto cultural na Casa Porto deu certo e a iniciativa rendeu prêmios e novos patrocínios ao longo de quatro anos. No entanto, passados os eventos da Copa do Mundo e das Olimpíadas, o Rio de Janeiro entrou em crise, junto com o fim do projeto Porto Maravilha e, sem patrocínios, Raphael se viu com dívidas e diante de mais um desafio.

\section{A CASA PORTO APÓS O FIM DO PROJETO PORTO MARAVILHA}

Refletindo sobre como contornar aquele momento, enquanto alugava sem muito sucesso o espaço para festas e shows, Raphael pensou em sua paixão pela culinária, faceta que também o havia tornado conhecido a ponto de ser convidado para eventos de gastronomia e de ser jurado de concursos pela cidade. Ele nutria paixão por receber amigos, para quem cozinhava, especialmente aos domingos, mas também por divulgar bares, na internet. Foi assim que, no início de 2018, transformou a Casa Porto em um botequim. Mas precisava gerar um atrativo para impulsionar os transeuntes a subirem a escada do casaráo para ali se deliciarem com o ambiente.

Com uma ordem de despejo em pleno Carnaval, Raphael recebeu ajuda de um amigo advogado (outro "anjo" em sua vida) para manter o contrato de aluguel do imóvel da Casa Porto. O cardápio do botequim foi entáo divulgado com a famosa coxinha de pernil que sua avó fazia, dando destaque à moela que também havia sido sua refeição barata em um boteco do centro ao longo da Faculdade de Filosofia. Mas não pretendia servir um prato comum de moela. Para incentivar a subida dos degraus da escada naquela portinha discreta, que dividia espaço com outros botecos na calçada, algo diferente deveria ser oferecido. Lançou, então, sua moela à milanesa.

Raphael cozinhava usando inicialmente apenas um fogareiro de camping com um minibotijão, maçarico e microondas. Contava com a aposta de fornecedores de cerveja, com quem ainda cultivava dívidas da fase anterior da Casa Porto, e com o apoio de amigos do ramo, de quem ganhou mesas, cadeiras e geladeiras, e de quituteiras da regiáo, donos de bar e amigos da cultura. Em 5 de março de 2018, a Casa Porto reabriu as suas portas, fortalecida pelo movimento coletivo de apoio. Assim, mesmo diante das dificuldades iniciais, mais uma vez a ideia de Raphael foi bem sucedida e passou a ser divulgada em seu espaço na rede social Facebook. Em junho daquele mesmo 
ano, Raphael já começava a quitar suas dívidas e a tornar a Casa Porto, versão botequim, conhecida.

Com demanda crescente e aumento no faturamento, Raphael reformou a cozinha e sentiu necessidade de um aporte maior de recursos. Um dia, em uma conversa com um conhecido, Raphael identificou uma pessoa que viria a ser seu sócio e que posteriormente traria mais um colega que também atuaria como segundo sócio investidor. Dentre os três, Raphael seria o sócio que atuaria diretamente na Casa Porto, tendo total autonomia para a tomada de decisóes. "Hoje eu tenho uma ideia e faço. Se eu fiz um prato e não vendeu, amanhã faço outro. Náo tenho compromisso em tudo dar certo. Meu único compromisso na Casa Porto é de fazer daquele lugar um lugar de experiências. É o local que eu gostaria de frequentar... que vende comida bacana, gostosa, mas que tem simbolismo. Atrai clientes que também viram amigos" declara Raphael.

E foi assim que a Casa Porto manteve a cara do seu criador. Quem acompanhava as publicaçóes em redes sociais como Instagram e Facebook, em 2020, imaginaria que Raphael teria uma equipe dedicada à sua movimentaçáo. Ledo engano, já que Raphael vinha fazendo tudo sozinho: respondendo cada comentário, postando cada foto e escrevendo cada publicação. "O Instagram sou eu", disse Raphael. Em suas postagens criativas, Raphael se divertia brincando com amigos, falando de política. "Comecei em março de 2018 com 50 seguidores, hoje temos 27 mil." Seu desembaraço com o uso das redes sociais garantia sua proximidade com os clientes, aspecto muito valorizado por Raphael em seu negócio.

Os conteúdos vinham sendo enriquecidos pelo que Raphael vivia no dia a dia na Casa Porto, onde optou por ser o chefe de cozinha, criando cardápios e receitas, papel acumulado com o de administrador. Raphael entendia que sua administração não se baseava em formação técnica, mas sim no instinto e na sua capacidade de ser autodidata, como o foi em muitos momentos de sua trajetória.

Nesse contexto, considerava que sua relação com a equipe, formada por 19 pessoas, era fruto de tudo o que experimentou ao longo de sua vida. "Não haveria para mim outra opção de trato com a equipe por conta de ... todas as frustraçôes que eu vivi e todas as relaçóes positivas também. Então eu queria trazer para a Casa Porto e isso, confesso, não foi pensado: vou tratar assim ou assado. Fui agindo de forma instintiva. Mas hoje vejo que foi fruto de tudo aquilo que fui vivendo, que fui passando. Entáo, eu queria montar uma empresa onde pessoas se sentissem à vontade e satisfeitas. Assim como eu me senti na Livraria Imperial com o Marcelo e na Editora Vieira \& Lent com a Cilene.”

Entre as práticas de gestão de pessoas na Casa Porto, Raphael citou: bar permanentemente aberto para o consumo livre de seus funcionários (open bar), adiantamento de salário para os que estáo passando por alguma dificuldade, incentivo à relação de igualdade entre os funcionários com perfis diferentes, envolvimento de todos em decisóes importantes. Essa cultura criada na Casa Porto fez com que as únicas demissóes ocorridas até 2020 fossem motivadas por situaçóes de desrespeito, inadmitido no local. "A relação humanizada com funcionários, para mim, é a única possível” reforçou Raphael. "Faço daquilo ali [Casa Porto] esta paixão... Eles são a base da casa. Então, quando eu não estou lá, eles que representam a Casa Porto.” Três funcionários da equipe eram clientes que frequentavam a Casa Porto e pediram para se juntar ao time. "São pessoas que vestem a camisa porque fazem parte daquilo... tem acolhimento... é difícil achar algo parecido", descreveu Raphael.

\section{A CRISE DO COVID-19 E A NECESSIDADE DE REINVENÇÃO DA CASA PORTO}

Mal havia passado a alegria do Carnaval, o mês de março de 2020 foi dominado pelos alertas sobre a crise da pandemia do COVID-19 e seus reflexos no Brasil. Em estágio avançado em outros países na Ásia e Europa, aqui ganhava dimensões aceleradas.

A decisão de fechar as portas foi inevitável e tornouse obrigatória para muitos estabelecimentos por orientaçóes do governo, que manteve a permissáo de abertura somente para os serviços considerados essenciais como supermercados, farmácias e postos de gasolina.

No mundo todo, as medidas de quarentena orientadas pela Organização Mundial da Saúde (OMS), em decorrência do avanço da pandemia, levaram à restrição na circulaçáo de pessoas, com consequentes impactos nas economias.

Segundo a Associação Brasileira de Bares e Restaurantes (Abrasel), o setor de bares e restaurantes figurava como um dos mais afetados pelas medidas de quarentena e consequente restrição na circulação da população. $\mathrm{O}$ impacto em potencial nos empregos do setor era preocupante. Paulo Solmucci, presidente da Abrasel, declarou em publicação de março de $2020^{4}$ : "Somos 1 milhão de estabelecimentos, $65 \%$ não têm nem CNPJ, e $80 \%$ deles faturam menos de $\mathrm{R} \$ 20$ mil por mês e têm no máximo dois funcionários. Esses $80 \%$ geram cerca de $20 \%$ de faturamento do setor, da ordem de R $\$ 250$ bilhóes, mas são responsáveis por quase metade dos empregos."

Alguns estabelecimentos conseguiram, ao menos na fase inicial do processo de fechamento de portas, manter os empregados em afastamento, sem decidir pela imediata demissão. Outros optaram por antecipar as férias dos funcionários, na tentativa de adiar perdas maiores ${ }^{4}$.

Mas, sem receita, a manutençấo do negócio e dos empregados passou a exigir tomadas de decisão alternativas por parte dos proprietários de bares, restaurantes e boates, enquanto permaneciam fechados, conforme destacado em 
reportagem da Agência Brasil EBC de 19 de março de 2020. Vouchers antecipando pagamentos para usufruto dos clientes após a reabertura dos estabelecimentos, assinaturas, promoçóes, manutenção de interação com clientes, especialmente via redes sociais, até a convocação de parte das equipes para apoiar na execução de alguns serviços, figuravam entre as alternativas acionadas por muitos estabelecimentos, entre eles a Casa Porto.

Depois de fazer uso de várias estratégias, a exemplo do Pendura Invertido, a adesão ao esquema de entregas foi a única opçáo possível identificada por Raphael para manter o pagamento de seus funcionários por mais tempo. Com a rapidez de adaptação, característica de Raphael, e com o apoio da recémcontratada "gerente de projetos", que desde janeiro o ajudava como o braço de execuçáo de suas ideias criativas, a tomada de decisão não lhe custou muito, assim como o entendimento de que só poderiam atuar nessa frente os empregados que morassem na região, se deslocando a pé para a Casa Porto.

Ainda que não estivesse conseguindo faturar o suficiente para seu próprio sustento, Raphael tinha como preocupação primordial preservar a saúde dos seus funcionários. Sua definição de saúde ia além da questáo do risco de contaminação pelo COVID-19: sentia-se responsável por oferecer uma sensação de segurança para sua equipe, levando-os a confiarem na preservação de seus empregos e salários de modo a minimizar as incertezas geradas pelo contexto da pandemia.

A tensão de prover segurança em meio a um período de muita instabilidade era enorme. Porém, mesmo diante de suas próprias dificuldades práticas e emocionais, mesmo com noites sem dormir, a responsabilidade de Raphael para com a sua equipe o fez seguir em busca de soluçóes para o desafio que enfrentava.

Embora as entregas estivessem garantindo o sustento inicial da Casa Porto, a ponto de não precisar demitir ninguém, Raphael estava insatisfeito com a adesão ao uso de aplicativos por alguns motivos:

a. Perímetro de entrega - Dada a localizaçâo de seu estabelecimento na Zona Portuária (Anexo 2) e o modo de funcionamento dos aplicativos, seu raio de entrega era limitado a alguns bairros que iam da Glória até o Maracanã. A "perda" era agravada pelo fato de que o próprio entorno da Casa Porto não representa uma região consumidora de delivery em potencial, por ser uma regiáo predominantemente comercial, ou seja, carente de público consumidor em potencial durante a pandemia.

b. Taxas cobradas - Ao escolher a modalidade que inclui o serviço de entrega pelo aplicativo (Anexo 3), a taxa cobrada variava de $22 \%$ a $30 \%$ do valor do pedido, impactando fortemente na receita final derivada das vendas.

c. Impossibilidade de acesso direto ao consumidor final - A ausência de contato direto com os consumidores impactava no modo de trabalho com o qual Raphael havia se habituado. Proximidade com clientes era sinônimo de ideias novas e de termômetro para aprimorar seu cardápio e seu negócio. A avaliação do próprio serviço de entrega ficava prejudicada com o uso dos aplicativos.

d. As condiçôes de trabalho dos entregadores - O conhecimento do modo de funcionamento dos serviços de entrega levou Raphael a entendê-lo como precário. Além dos baixos valores recebidos pelos profissionais a cada entrega, levando-os a cumprirem jornadas de trabalho extenuantes (superando muitas vezes 12 horas de trabalho diárias para garantir uma renda mínima de sustento no final do mês), a ausência de seguros ou garantias em caso de doença ou acidente, os custos com equipamentos para a realização das entregas (a exemplo das mochilas com a marca dos aplicativos) e para proteção contra a contaminação pelo COVID-19 sendo arcados exclusivamente pelos entregadores, justificavam a percepçáo de precarizaçáo. Além disso, ao ler sobre o impacto dos aplicativos para os pequenos negócios, como, por exemplo, na reportagem da BBC News Brasil, São Paulo de 08 de fevereiro de 2020, Raphael passou a questionar ainda mais se essa parceria seria benéfica para a manutenção da Casa Porto.

Eram três horas da madrugada do dia 8 de abril de 2020 e Raphael ainda não tinha conseguido dormir. Já haviam se passado três semanas desde o fechamento do atendimento presencial e do início do serviço de entregas por aplicativos. Alguns dos restaurantes próximos decidiram fechar as portas temporariamente, outros definitivamente. Uma decisão deveria ser tomada com urgência. Ele sabia que precisava agir para mudar a forma de prestação de serviço à qual estava momentaneamente submetido. Mas o que fazer? Dentre os inúmeros projetos que borbulhavam na cabeça sempre inquieta de Raphael, começou a surgir o de ter uma frota própria de entregadores. Mas como distribuir as tarefas entre os funcionários? Quais parcerias estabelecer? Quais ferramentas usar? Existiriam outras alternativas além da formação de uma frota de entregadores? Quais? A única coisa que Raphael sabia era que fechar definitivamente as portas não era uma opção.

\section{NOTAS}

1. RJ registra 92 mortes pelo novo coronavírus. G1. Retrieved from https://g1.globo.com/rj/rio-de-janeiro/noticia/2020/04/08/casosde-coronavirus-no-rj-em-8-de-abril.ghtml

2. Coronavírus: Bares do Rio se reinventam para não fecharem as portas e agradar clientes. O Globo. Retrieved from https:// oglobo.globo.com/sociedade/coronavirus-servico/coronavirusbares-do-rio-se-reinventam-para-nao-fecharem-as-portas-agradarclientes-24315164

3. Projeto de revitalização urbana da Regiáo Portuária do Rio de Janeiro envolvendo o Poder Público e a iniciativa privada.

4. Coronavírus e o bolso: "Ninguém que está vivo no Brasil hoje viu algo tão sério". Agência de Jornalismo Investigativo. Retrived from: https://apublica.org/2020/03/coronavirus-e-o-bolso-ninguemque-esta-vivo-no-brasil-hoje-viu-algo-tao-serio/ 


\section{ANEXO A. ATIVIDADES DA CASA PORTO}

"As atividades, sempre gratuitas, objetivam compartilhar as riquezas culturais por meio de eventos temáticos, com a participaçáo de convidados especiais. A semana começa com o Silêncio na Biblioteca, onde escritores, editores ou livreiros batem um papo sobre o mundo dos livros. Nas terças-feiras é a vez do Arte do Encontro, sempre com artistas da região portuária (cineastas, músicos, artistas plásticos) que conversam sobre suas obras. Nas quartas-feiras acontece o Tabuleiro da Baiana, focado na cultura afro-brasileira, quando convidados fazem debates e oficinas de ritmos e danças. Às quintas, a Casa recebe projetos de todas as expressóes artísticas, apresentando sempre uma novidade, como, por exemplo, a oficina Passos Populares, que já fez muita gente dançar o jongo, ou a mostra Rio Web Fest, um festival internacional de web series. Para fechar a semana, a sextafeira é livre, e a Casa funciona apenas como galeria, café e bar, mas que sempre pode surpreender, como em uma ação criativa feita especialmente para o público infantil.

Casa Porto também realiza o programa Porto Criativo, uma incubadora de consultoria de projetos, para moradores da regiáo. $\mathrm{O}$ atendimento é gratuito e a Casa compartilha uma estrutura com internet de alta velocidade, ar condicionado, mesa de trabalho em conjunto, sala de repouso, biblioteca com 5 mil títulos e outra virtual, auditório equipado para reunióes e palestras, além de disponibilizar consultores e promover vivências e atividades disciplinares.

Outros eventos, como festas juninas e comemoraçóes, estão sempre sendo produzidos para ocupar também o Largo da Prainha e arredores, atraindo público de outros bairros e gerando renda para os moradores. Um dos grandes destaques é o Fim de Semana do Livro no Porto (FIM), um festival literário de grande sucesso, que já teve três edições.

Com o sugestivo slogan 'Ideias de portas abertas', a Casa Porto merece todo o apoio pela relevância de suas atividades que vêm transformando a realidade dos cariocas, especialmente a dos moradores da regiáo."

Fonte: http://guiaculturalcentrodorio.com.br/casa-porto/, recuperado em 13 de julho de 2020. 


\section{ANEXO B. LOCALIZAÇÃO DA CASA PORTO}

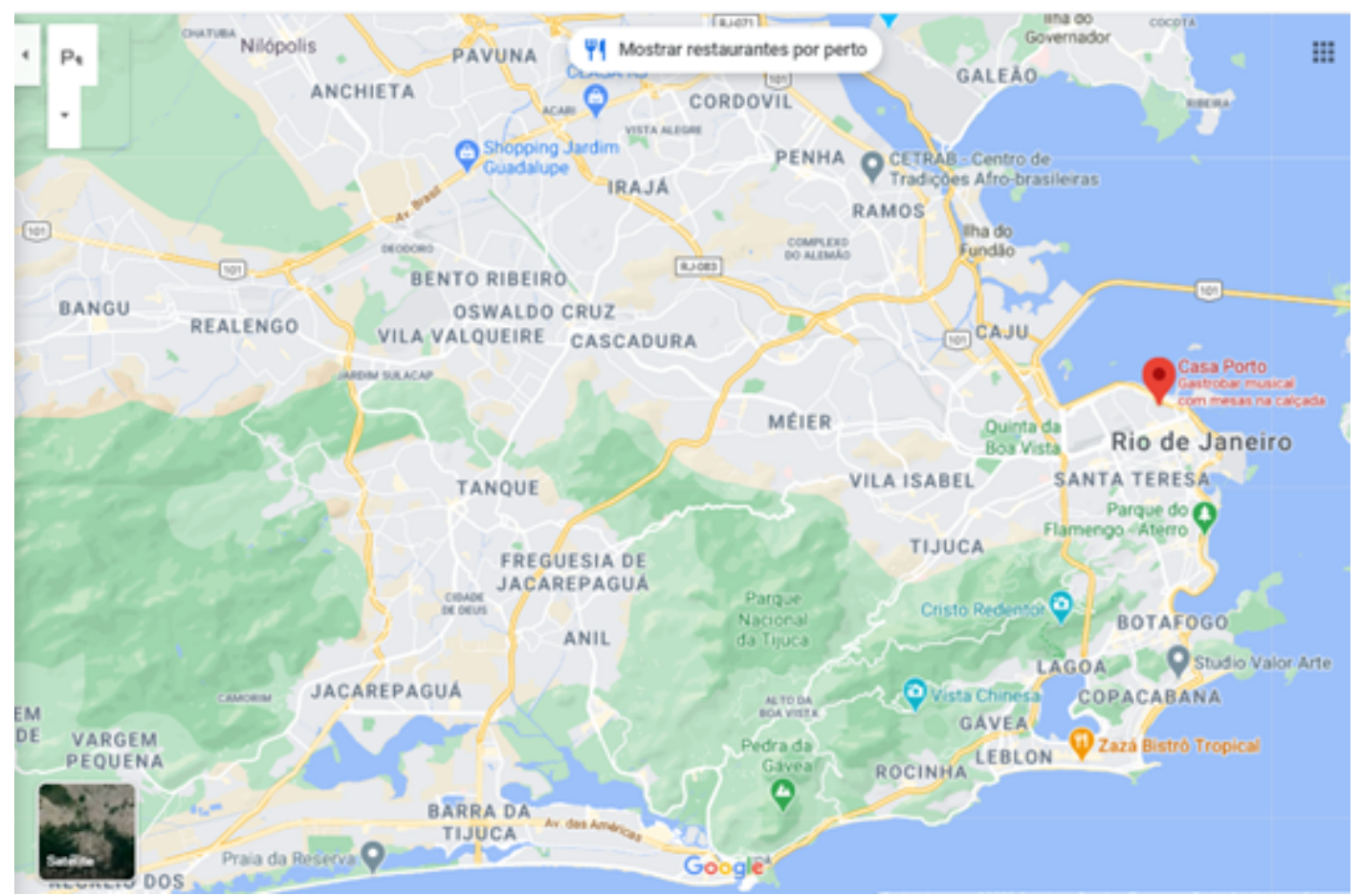

Figura B1. Localização da Casa Porto.

Fonte: Google Maps. 


\section{ANEXO C. PLANOS IFOOD}

\section{Plano Básico}

- Entrega feita pelo restaurante

- Taxa de $12 \%$ sobre o valor de todos os pedidos e mais 3,5\% em pedidos com pagamento via iFood

- Mensalidade de R\$100 por mês, apenas se você faturar mais do que R\$1.800 mensais.

\section{Plano Entrega}

- Entrega feita por entregadores parceiros do iFood

- Taxa de $27 \%$ sobre o valor de todos os pedidos

- Mensalidade de R\$130, apenas se faturar mais do que R\$1.800 mensais

Fonte: https://parceiros.ifood.com.br/restaurante recuperado em 13 de julho de 2020. 


\section{Notas de Ensino}

\section{RESUMO}

O caso de ensino descreve a trajetória do empreendedor Raphael Vidal. As informaçōes apresentadas possibilitam vincular a história e as crenças do sujeito-empreendedor Raphael às decisóes referentes ao empreendimento Casa Porto no contexto da pandemia do COVID-19. Aspectos de sua postura empreendedora como base para a forma como vem conduzindo a Casa Porto são evidenciadas, assim como são resgatados elementos relacionados à decisão de abrir, conduzir e manter um negócio diante de situaçôes de crise. Adicionalmente, são abordadas nuances relativas a outras esferas envolvidas no entendimento do empreendedor como um ser social.

Palavras-chave: caso para ensino; empreendedorismo; empreendedor humanizado; COVID-19; crise.

\section{FONTE DE DADOS}

O caso foi redigido a partir de informaçõessecundárias obtidas em diversos sítios da internet (referenciados), em uma entrevista realizada com o próprio Raphael Vidal e em múltiplas mensagens de texto, áudio e vídeo trocadas com o empreendedor via e-mails e WhatsApp ao longo da construçáo do caso. O caso conta com uma autorização de Raphael Vidal para publicação.

\section{OBJETIVOS EDUCACIONAIS}

O presente caso tem o objetivo de permitir aos alunos compreender aspectos envolvidos na geração de um novo negócio, destacadamente o papel do empreendedor, e o impacto do seu estilo, sujeito social, no processo de tomada de decisão em contextos de crise.

\section{ABSTRACT}

This teaching case describes the trajectory of the entrepreneur Raphael Vidal. The information presented makes it possible to link the history and beliefs of the subject-entrepreneur Raphael to the decisions regarding Casa Porto project in the context of the COVID-19 pandemic. Aspects of his entrepreneurial attitude as a basis for the way he has been conducting Casa Porto are exposed. In addition, elements related to the decision to open, conduct, and maintain a business in situations of crisis are displayed. And more importantly, nuances related to other spheres involved in the understanding of the entrepreneur as a social being are addressed.

Keywords: teaching case; entrepreneurship; humanized entrepreneur; COVID-19; crisis.
A proposta é fazer com que os alunos analisem a trajetória empreendedora de Raphael Vidal e discutam sobre as possíveis alternativas para o seu negócio em um contexto de pandemia, propondo soluçóes coerentes com o perfil do empreendedor humanizado para os dilemas retratados.

O caso foi desenvolvido de modo a possibilitar a exploraçáo de conceitos relacionados a empreendedorismo e gestão de pessoas, podendo ser aplicado nos cursos de graduação em Administração, em disciplinas de Empreendedorismo, Comportamento Organizacional, Gestão de Serviços ou qualquer outra disciplina que aborde os temas aqui tratados. 


\section{PLANO DE AULA}

Para a condução da atividade, sugerem-se as seguintes etapas:

- Disponibilização do material: propóe-se que o docente disponibilize o caso com antecedência mínima de uma semana para os discentes.

- Preparação prévia individual: propóe-se que o docente demande que os discentes leiam o caso e preparem antes da aula um pequeno relatório, de ao menos uma lauda, com as principais informaçóes do caso, incluindo o dilema enfrentado por Raphael Vidal sobre o serviço de entrega durante a pandemia. $\mathrm{O}$ relatório individual deverá ser levado para o debate em pequenos grupos.

- Discussão em pequenos grupos: propóe-se a divisão da turma em grupos de no mínimo três e no máximo cinco alunos para a discussão sobre o caso na busca de soluçóes para os problemas apresentados.

- Discussão plenária: propóe-se um debate com toda a turma. Cada grupo deve apresentar as suas ideias e proposiçóes. Aconselha-se que o docente estimule o debate por meio de perguntas auxiliares que encorajem os discentes a descreverem e defenderem com clareza as soluçóes propostas e pontos de vista apresentados. Exemplos de perguntas auxiliares: Descreva melhor o ponto $\mathrm{x}$ da sua proposta. Por que você acha que Raphael deve agir dessa forma? Qual a coerência entre a sua proposta e a trajetória de Raphael? Qual seria o objetivo dessa iniciativa? $O$ que você espera que Raphael alcance fazendo isso?

\section{SUGESTÃO DE PLANEJAMENTO PARA DISCUSSÃO DO CASO}

Dilema: Raphael se perguntava como poderia manter seu negócio e o salário de seus funcionários em meio à crise causada pela pandemia do COVID-19.

Questóes de aquecimento para a discussáo em pequenos grupos: Descreva as diversas decisóes e iniciativas profissionais de Raphael Vidal ao longo de sua vida. O que elas dizem a respeito das motivaçóes de Raphael e de sua forma de empreender?

Questōes para a discussão plenária: (1) Dado o contexto apresentado pelo caso "Casa Porto", qual solução você propõe para o empreendimento? Detalhe a sua proposta e explique em que medida a sua solução é condizente com a trajetória/ história de vida de Raphael Vidal; (2) Destaque as principais características individuais de Raphael que o influenciaram nas suas decisôes de empreender ao longo da vida.

\section{ANÁLISE DO CASO E ANÁLISE/PROCESSO DE ENSINO}

O caso pode ser utilizado para introduzir as teorias sobre empreendedor humanizado e perfil empreendedor. A Tabela 1 sintetiza a organização de uma aula com duração de duas horas.

Tabela 1. Plano de aula.

\begin{tabular}{ll}
\hline \multicolumn{1}{c}{ Plano de aula } & Duração \\
\hline Introdução e divisão dos pequenos grupos & 20 minutos \\
Discussão em pequenos grupos & 30 minutos \\
Discussão plenária e introdução da teoria & 60 minutos \\
Encerramento & 10 minutos \\
\hline
\end{tabular}

\section{Discussão Plenária - Parte 1}

A sessão plenária deve ser iniciada com a pergunta (1) que remete ao dilema de Raphael Vidal: Dado o contexto apresentado pelo caso "Casa Porto", qual solução você propóe para o empreendimento? Detalhe a sua proposta e explique em que medida a sua solução é condizente com a trajetória/história de vida de Raphael Vidal.

Sugerimos que na primeira parte da discussão seja dado um enfoque nas soluçóes propostas pelos alunos e na trajetória de vida de Raphael para estabelecer a ligação entre o caso e a teoria de empreendedorismo humanizado. À medida que os alunos forem expondo suas ideias, o professor deve anotar no quadro, no Power Point ou em qualquer ferramenta disponível, os elementos apresentados pelos participantes de modo a utilizar essas informaçóes para introduzir o conceito de empreendedorismo humanizado e para identificar Raphael como um empreendedor humanizado.

Não é necessário que os alunos cheguem a um consenso, bastando que os participantes: (1) demonstrem que compreenderam o contexto e o dilema; (2) proponham e defendam as soluçóes apresentadas; (3) argumentem a relação entre suas propostas e as características de Raphael e sua trajetória/história de vida.

\section{Contextualização Teórica - Empreendedorismo Humanizado}

O fenômeno do empreendedorismo impede que ele seja resumido à dimensão de abertura de uma empresa. Cada vez mais defende-se, portanto, uma visão multidimensional do fenômeno (Danjou, 2002), e também da definição do empreendedor, que varia conforme as lentes epistemológicas 
usadas ao longo do tempo (Guimarães, 2019). Nessa tentativa de oferecer um olhar multidimensional sobre o fenômeno empreendedorismo, resgata-se a questáo de subjetividade do sujeito-empreendedor e ganham importância sua capacidade de ser um sujeito reflexivo com açóes dotadas de sentido (Schön, 1995) e os aspectos emocionais e as experiências vivenciadas (que para algumas correntes são evidenciados pelo uso do método de investigação da história de vida dos sujeitos), nem sempre incluídos nas investigações no campo das organizações (Gaulejac, 2005; Legrand, 1993; Paiva, Almeida, \& Guerra, 2008).

O conceito de empreendedor humanizado surge no contexto de uma leitura crítica sobre o fenômeno empreendedor, em contraposição à leitura utilitarista e individualista comumente empregada (Paiva et al., 2008).

A base do conceito reside no entendimento de que a relação múltipla com o outro é base para a constituição do ser humano, sendo o empreendedor humanizado aquele que "está em constante construção social da realidade como refinamento de si mesmo e dos outros, envolvidos em seu projeto realizador" (Paiva et al., 2008, p. 119).

Portanto, do ponto de vista de uma perspectiva interacionista, compreende-se que para além de características individuais, deve-se levar em conta que a constituição do empreendedor se baseia fortemente nas relaçôes que mantém com o outro. "O empreendedor humanizado emerge como um ser relacional, em lugar do herói solitário" (Paiva et al., 2008, p. 120), visão que contrapóe a corrente psicossocial do sujeito-empreendedor à do empreendedor atomístico.

Adicionalmente, pode-se dizer que o empreendedor humanizado tem um compromisso com a experiência vivida nas dimensóes de passado, presente e futuro, o que o leva a resgatar um significado nas suas relações sociais, familiares e de trabalho. Nesse contexto, ele "integra a objetividade do trabalho com a subjetividade da pessoa e também demonstra responsabilidade social com a realidade" (Chanlat, 1996 como citado em Paiva et al., 2008, p. 127). Protagonizado por Lester, esse empreendedor pressupóe a prática oriunda da experiência, permitindo apontar outros relacionamentos de interação humana, sempre em relação a recomeçar, a criar e a recriar. Isso parece pressupor a existência de responsabilidades e de construçóes decorrentes de uma aposta na autoconfiança.

\section{Análise do perfil de Raphael Vidal como empreendedor humanizado}

Uma análise do estilo de empreendedorismo de Raphael Vidal pode ser realizada com base nas decisóes tomadas na posiçáo de sujeito empreendedor, e resgatando aspectos e fatos de sua trajetória de vida. Sua atuação, mesmo antes de transformar a Casa Porto em um bar, revela uma ação empreendedora de natureza engajada com dimensóes da realidade social. Apoiar a comunidade local e incentivar os negócios do entorno sáo parte do dia a dia e de sua lógica empreendedora.

A dimensão relacional (Paiva et al., 2008) é um traço marcante na história de Raphael, tendo sido base para a construção de seu perfil empreendedor e para a fonte de aprendizado que diz levar para seu negócio atual. Além disso, ela foi importante fonte de cultivo da postura não utilitarista, permitindo que Raphael sempre caminhasse na direção de seus projetos idealizados.

Tanto com Marcelo, dono da Livraria Imperial, quanto com Cilene (da Editora Vieira \& Lent), Raphael declara ter aprendido "como tratar o funcionário", "o lado digno do trabalho", o valor de uma postura generosa para investir em alguém que não tem total experiência no ramo (como uma aposta) e para apoiar pessoas em dificuldade (seja no momento de busca de emprego, seja ao sair dele). "Tudo que estou fazendo agora é só reprodução do que eu vivi com a Cilene e com Marcelo. São duas pessoas que são referências na minha vida de como que é possível ter um olhar para o funcionário para além da questão empresarial, sabe, da questáo de resultado, sabe, de resultado financeiro" declara Raphael.

Esse aprendizado foi reforçado com sua relação com diversos atores fundamentais para que a FIM acontecesse (de patrocinadores a grandes nomes de assessoria de imprensa e produção cultural), em um contexto em que prevaleceu a relaçáo humana e a crença na viabilidade de um empreendimento sem recursos, à dimensão utilitarista, financeira.

Essas dimensôes aprendidas ao longo de sua trajetória fizeram com que, em seu empreendimento, Raphael também mantivesse o desejo de tratar seus empregados com respeito, igualdade e justiça. Oferecer um open bar em horário de expediente, para usufruto dos funcionários, tem um simbolismo importante e reflete o desejo de Raphael de tornar o ambiente de trabalho um espaço harmonioso, sem o peso das estruturas formais comumente encontradas nas organizaçóes. Além disso, "adiantamento de salário para os que estáo passando por alguma dificuldade, incentivo à relaçáo de igualdade entre os 19 funcionários com perfis diferentes, envolvimento de todos em decisóes importantes" também refletem a intenção de tratar sua equipe de maneira atenciosa.

Quanto às decisóes tomadas ao longo de sua trajetória, seu aspecto inquieto, reivindicador, que não se aquieta diante do pensamento e de posturas tidas como hegemônicas no mundo organizacional, permite que se 
reforce a compreensão de Raphael enquanto empreendedor humanizado. Empregos ou fontes de renda estáveis, como no MAR, ou na livraria do Leblon, não permitiram que ele abrisse máo de suas crenças no que de fato seria o correto do ponto de vista de relaçáo laboral e o que poderia dar sentido ao trabalho por ele realizado. Paiva, Almeida e Guerra (2008) descrevem que essa postura emancipatória do empreendedor humanizado, entretanto, exige tempo, para que não haja ruptura radical com as condiçôes socioculturais do ambiente empreendedor, propiciando um espaço/tempo de adaptação.

Já no contexto pandêmico, sua postura não foi diferente: "Foram as únicas atitudes possíveis. A única coisa que eu podia fazer era deixar a galera que pega transporte público de quarentena em casa. A única coisa possível. Não passa pela cabeça. Pela minha, por toda a experiência que passei na minha vida”, diz Raphael.

Raphael não vê sentido em empreender se não for com o pensamento de bem-estar dos que o cercam. E vai além do grupo de empregados, incluindo o bem-estar da comunidade onde está inserido.

\section{Alternativas de Ação-Empreendedorismo Humanizado}

Ao conduzir a discussão sobre as possíveis soluções para o dilema enfrentado pelo empreendedor do caso, o professor deve ajudar os participantes a analisar o quanto as propostas apresentadas fogem do enfoque tradicional, utilitarista, pragmático e baseado na autoconfiança individualista e incorporam aspectos da interação humana e da responsabilidade do empreendedor com seus funcionários diante dos desafios impostos pelo contexto pandêmico.

Nesse sentido, as soluções poderiam se aproximar da abordagem humanista na medida em que consideram um ou mais dos seguintes elementos: o tratamento digno e o apoio aos funcionários no momento de dificuldade, a realidade da comunidade do entorno do restaurante, as oportunidades de trabalho que poderiam vir a surgir com a solução proposta, a postura emancipatória de Raphael diante das estruturas e práticas hegemônicas, a informalidade e a criatividade do empreendedor, a forma como Raphael constrói e mantém suas parcerias com empregados, fornecedores e clientes, assim como o seu empenho e carisma para obter apoio e patrocínio.

Fechar o negócio não era uma opçáo para Raphael. Dentre as alternativas possíveis naquele momento, ele poderia:

1. Tentar manter o uso de aplicativos tipo iFood e Uber Eats devido à divulgaçáo que eles proporcionam, mas utilizar a frota própria para a entrega, diminuindo assim as taxas cobradas e garantindo o tratamento digno aos entregadores. A frota poderia ser composta por moradores do entorno da Casa Porto.

2. Criar um aplicativo ou meio eletrônico próprio para receber e gerenciar os pedidos e as entregas, tornandose mais independente dos aplicativos comerciais.

3. Alavancar as vendas por meio de uma abordagem direta com os clientes fiéis à Casa Porto por meio das mídias sociais.

4. Fechar as portas temporariamente e manter o negócio por financiamento por meio de "vaquinhas virtuais" ou pelo patrocínio de um dos novos sócios ou de outra pessoa da rede de contato de Raphael.

\section{Discussão plenária - Parte 2}

Sugerimos que na segunda parte da discussão seja dado um enfoque nas principais características individuais de Raphael que estejam de acordo com as teorias de perfil empreendedor a partir da pergunta:

1. Destaque as principais características individuais de Raphael que o influenciaram nas suas decisóes de empreender ao longo da vida.

À medida que os alunos forem expondo suas ideias, o professor deve anotar no quadro, no PowerPoint ou em qualquer ferramenta disponível, as características individuais de Raphael destacadas pelos alunos, focando a sua atenção em identificar os elementos que ajudam a ilustrar o impacto das características individuais de Raphael Vidal nas suas decisões empreendedoras.

\section{Contextualização Teórica - Perfil Empreendedor}

Para Shane e Venkataraman (2000), o empreendedorismo é o campo de estudos sobre como, por quem, e com que efeitos as oportunidades de criar futuros bens e serviços são descobertas, avaliadas e exploradas. Como consequência, os estudos sobre empreendedorismo devem abranger a descoberta, a avaliação e a exploração de oportunidades, assim como o grupo de indivíduos que descobrem, avaliam e exploram estas oportunidades (Shane \& Venkataraman, 2000; Shook, Priem, \& McGee, 2003).

Shook, Priem e McGee (2003) destacam o papel que as características do indivíduo, o empreendedor, desempenham nas etapas de formaçáo de um empreendimento - intenção empreendedora, busca e descoberta de oportunidades, decisão de exploração e atividades envolvidas na exploração até a primeira venda.

Sobre intenção empreendedora, que seria a intenção de criar um negócio, Shook et al. (2003) observam que a 
literatura sobre o tema foca na percepção individual sobre a possibilidade, vontade e suportes sociais para o início de um novo negócio. Autonomia, as características demográficas e a autoeficácia são apresentadas como fatores importantes para o desenvolvimento da intenção empreendedora.

Shane e Venkataraman (2000) definem oportunidades como "situações em que novos produtos, serviços, matériaprima, e métodos de organização podem ser introduzidos e vendidos a um preço maior do que o custo de produção ... requer a descoberta de novas relaçóes entre os meios e os fins" (Shane \& Venkataraman, 2000, p. 220). Logo, a ideia de oportunidades estaria ligada à ideia da criaçâo de algo novo. Nesse sentido, empreendedorismo não requer, mas pode incluir a criação de novas empresas.

Ainda segundo Shane e Venkataraman (2000), uma descoberta ocorreria quando "alguém faz a conjectura de que um conjunto de recursos não é colocado no seu 'melhor uso"' (Shane \& Venkataraman, 2000, p. 220). Dois fatores influenciariam a descoberta: a posse das informaçóes, a identificaçáo de uma oportunidade; e as propriedades cognitivas necessárias para valorizá-la.

Sobre a decisão de explorar uma oportunidade, Shane e Venkataraman (2000) destacam tanto as características da oportunidade quanto a natureza do indivíduo. Oportunidades com maior valor esperado seriam as exploradas. As diferenças entre os indivíduos contemplariam: ponderação entre o valor da oportunidade e os custos para gerar esse valor e para gerar valor de outras formas; os custos para obtenção de recursos necessários para explorar a oportunidade; laços sociais fortes com provedores de recursos, que facilitariam a aquisiçáo de recursos e aumentariam a probabilidade de exploração de oportunidades; o desenvolvimento de informaçóes úteis para o empreendedorismo a partir de um emprego anterior; a transferência de informaçóes da experiência anterior à oportunidade; a experiência empreendedora anterior. A decisão de explorar uma oportunidade empreendedora também seria influenciada por diferenças individuais nas percepçóes, na vontade de suportar riscos, no otimismo, na maior tolerância à ambiguidade, no maior desejo por realização. Por fim, segundo os autores, pessoas com maior autoeficácia e lócus interno de controle seriam mais propensas a explorar oportunidades. Shook et al. (2003) destacam a propensão ao risco, motivaçóes e atitudes como atributos psicológicos com possível influência na decisão de explorar uma oportunidade empreendedora.

\section{Análise de Raphael Vidal de acordo com a teoria sobre perfil do empreendedor}

Um modo de identificar o perfil empreendedor de Raphael Vidal pode ser a partir da análise de suas características individuais que influenciaram a decisão de explorar as oportunidades empreendedoras que surgiram ao longo de sua vida.

Alguns dos atributos psicológicos destacados por Shook et al. (2003) - propensão ao risco, motivaçóes e atitudes - e das características individuais apontados por Shane e Venkataraman (2000) - vontade de suportar riscos, otimismo, maior tolerância à ambiguidade, maior desejo por realização - podem ser identificados na trajetória de Raphael.

A busca pelos sonhos de conhecer e conviver com escritores, de trabalhar com o mercado editorial e de se tornar um escritor estáo presentes em seus relatos e em sua história. Diante das dificuldades e das inúmeras escolhas complexas e permeadas de riscos, o empreendedor mantinha otimismo e desejo por realizar os seus ideais.

No entanto, a propensão de Raphael a suportar riscos é marcante e evidenciada diversas vezes em sua trajetória. Entre as evidências do caso, podemos destacar:

- Sua saída de casa aos 13 anos de idade.

- O pedido de demissão ou planejamento da saída de um emprego sempre que estava insatisfeito com um trabalho, mesmo sem poder prever se o seu próximo passo seria bem sucedido ou não. Exemplos: ao buscar oportunidades em editoras enquanto trabalhava na livraria no Leblon, ao negociar a sua saída do MAR, ao sair do emprego em uma editora grande para iniciar o projeto Festival Literário no Morro da conceição (FIM).

- A predisposição para buscar oportunidades de trabalho e projetos com os quais ainda náo tinha experiência, mas dotado de uma imensa vontade de aprender e de concretizar ideias. Assim o fez quando: (1) se apresentou para Marcelo, dono da Livraria Imperial, e iniciou um trabalho de gestáo sem nunca ter tido tal experiência; (2) enviou o seu currículo para diversas editoras até ser contratado por Cilene, não obstante a ausência de bagagem como editor; (3) montou o projeto de um Festival Literário no Morro da Conceição (FIM) e buscou o patrocínio necessário, a despeito da sua inexperiência com o ramo de produção de eventos de tal porte.

Shane e Venkataraman (2000) destacam também que laços sociais fortes com provedores de recursos facilitam a aquisição destes e aumentam a probabilidade de exploração de novas oportunidades. Raphael Vidal, durante toda a sua trajetória empreendedora, demonstrou ter habilidades não apenas para acionar a sua rede em potencial de fornecedores e investidores, como também para criar os vínculos de 
confiança necessários com fornecedores e patrocinadores para a efetivação de um empreendimento.

Entre as evidências do caso podemos citar: o apoio de Marcelo ao projeto de bate-papo com escritores; a obtenção e patrocínio (prefeitura, Light), apoio de produção (Cláudia Noronha e Bel Fernandes) e operacional (trabalhadores da região) para o projeto FIM; a obtenção de recursos para tornar a Casa Porto um centro cultural, que incluía entre suas atividades a capacitaçáo profissional da máo de obra local, fortalecendo ainda mais os laços entre o empreendedor e os fornecedores locais de serviços; a ajuda de uma amiga advogada que lhe prestou serviços de assessoria para que ele conseguisse se manter no imóvel em um período de dificuldade; boa relaçáo com os fornecedores de cerveja, donos de restaurantes, cozinheiras da região e amigos que o ajudaram a reinaugurar a Casa Porto como botequim; o aporte financeiro de dois sócios que investiram no sonho de Raphael.

Por fim, o desenvolvimento de informações úteis para o empreendedorismo a partir de um emprego anterior, a transferência de informaçóes da experiência anterior à oportunidade, e a experiência empreendedora anterior (Shane \& Venkataraman, 2000) também estão presentes na história de Raphael. Muito embora a trajetória desse empreendedor seja caracterizada pela diversidade de atividades em múltiplos empregos e empreendimentos, o acúmulo de experiências relacionadas à área da cultura ajudou-o a desenvolver habilidades técnicas e interpessoais que se manifestaram principalmente na decisão de iniciar e manter o empreendimento da Casa Porto.

A experiência com o projeto FIM o ajudou na formatação da Casa Porto como centro cultural e a sua paixão por culinária foi importante quando o empreendimento foi transformado em botequim. Não obstante, os empregos anteriores com Marcelo e Cilene foram, segundo o próprio Raphael, referências essências sobre como tratar funcionários com dignidade e respeito.

\section{DESFECHO}

A Casa Porto não é apenas um negócio para Raphael, é uma extensáo de sua vida. Antes da pandemia de COVID-19, ele não trabalhava com delivery, mas aderiu ao serviço como a grande maioria dos restaurantes fez para contornar as restriçóes governamentais de atendimento ao público.

Insatisfeito com as taxas dos aplicativos de entrega e indignado com as condiçóes precárias a que eram submetidos os entregadores, Raphael decidiu montar sua própria frota de entrega com a ajuda de sua recém-contratada gerente de projetos.
Embora não tivesse experiência em administrar a nova ideia - como já havia acontecido tantas outras vezes em sua trajetória -, Raphael observou que os mototaxistas no entorno da Zona Portuária estavam ociosos e chamou dois amigos que moravam perto da Casa Porto (um mototaxista e um motorista de Uber) e começou o seu serviço de entrega independente com um perímetro maior do que o usado pelos aplicativos, chegando a regióes como Gávea e Meier. Para apoiar, montou uma estrutura de WhatsApp específica para os pedidos independentes, permitindo que os pedidos fossem recebidos pelos garçons, responsáveis pela administração do serviço de delivery.

A ideia era manter a plataforma de aplicativos, mas priorizar o uso da frota independente. Em duas semanas, a demanda por plataformas iFood e Uber Eats passou a representar apenas 5\% dos pedidos. Em suas redes sociais, Raphael intensificou o contato com seus clientes para pedir apoio ao seu negócio e para fortalecer o canal de entregas próprio. Seus esforços renderam resultados que se refletiram em maiores margens, diminuição dos custos e aumento no número de pedidos. Essa ação, junto com o retorno do Pendura Invertido, garantiu o adiantamento dos salários dos funcionários até o mês de agosto de 2020 e a contratação de mais três novos colaboradores.

Pouco mais de três meses depois do início do serviço, a Casa Porto passou a contar com uma frota de sete motos e um carro, que chegou a efetuar mais de mil entregas no mês de junho com o apoio da plataforma Delivery do Bem. Todos os entregadores lograram diárias que permitiram uma renda mensal em torno de $\mathrm{R} \$ 1.400,00$ para uma carga horária semanal de trabalho de 40 horas. Além disso, a Casa Porto garantiu o fornecimento de almoço e lanche, cesta básica, equipamentos acessórios (apoio de celular, bolsa mochila, máscara, álcool em gel, cinta de coluna), premiaçáo, entre outros benefícios. Raphael passou a se reunir todas as terçasfeiras com a equipe e demonstrar sua preocupação com os entregadores, escutando ativamente suas demandas e pensando em soluçóes para os novos desafios.

A iniciativa rendeu retorno financeiro e a Casa Porto passou a registrar faturamento sustentado. $\mathrm{Na}$ segunda quinzena de março, o faturamento foi de $\mathrm{R} \$ 21.649,00$; em abril, mês no qual o serviço de entrega independente começou a funcionar na segunda quinzena, o faturamento foi de $\mathrm{R} \$$ 69.300,68; nos meses de maio e junho, os faturamentos foram de $\mathrm{R} \$ 70.786,87$ e $\mathrm{R} \$$ 98.975,73, respectivamente.

Porém, diante das incertezas geradas pela crise da pandemia, Raphael pondera, observa e avalia seus próximos passos para agir em prol náo só da perpetuaçáa de seu empreendimento, mas também de apoio ao entorno e aos restaurantes e negócios cariocas ligados à alimentação. Ideias de projetos náo faltam na cabeça criativa de Raphael. 


\section{REFERÊNCIAS}

Danjou, I. L' (2002). L'entrepreneuriat: Un champ fertile à la recherche de son unité. Revue Française de Gestion, 28(138), 109-125. Retrieved from https://www. econbiz.de/Record/l-entrepreneuriat-un-champ-fertile\%C3\%A0-la-recherche-de-son-unit \%C3\%A9-danjouisabelle/ 10001723646

Gaulejac, V. de. (2005). História e historicidade. In V. de Gaulejac; S. R. Marquez \& E. T. Ruiz (Orgs.), História de vida: Psicoanálisis y sociología clinica (pp. 61-90). México: Edición de la Universidad Autónoma de Querétaro.

Guimarães, E. H., Jr, (2019). Como os empreendedores trabalham: Uma leitura psicodinâmica da organização do trabalho de um grupo de empreendedores. Revista de Empreendedorismo e Gestáo de Pequenas Empresas, 8(1), 149-175. Retrieved from https://www.regepe.org.br/regepe/article/view/889/pdf

Legrand, M. (1993). Le récit de vie. In M. Legrand. L'approche biographique (pp. 178-241). Marseille: Hommes et Perspectives.

\section{Autoria}

\section{Valéria Quiroga Vinhas}

Universidade Federal do Rio de Janeiro, Instituto COPPEAD de Administração

Rua Pascoal Lemme, no 355, Cidade Universitária, 21941-918, Rio de Janeiro, RJ, Brasil.

E-mail:vqv@hotmail.com

(D) https://orcid.org/0000-0002-8591-0825

\section{Ana Luiza Szuchmacher Verissimo Lopes*}

Universidade Federal do Estado do Rio de Janeiro, Departamento de Estratégia de Gestão

Rua Voluntários da Pátria, no 107, Botafogo, 22270-000, Rio de Janeiro, RJ, Brasil.

E-mail: ana.lopes@unirio.br

(D) https://orcid.org/0000-0001-7439-4979

* Autora Correspondente

\section{Financiamento}

As autoras relataram que não houve suporte financeiro para a pesquisa deste artigo.

\section{Conflito de Interesses}

As autoras informaram que não há conflito de interesses.

\section{Direitos Autorais}

A RAC detém os direitos autorais deste conteúdo.
Paiva,F.G.,Jr,Almeida,S.L., \&Guerra,J.R.F.(2008).Oempreendedor humanizado como uma alternativa ao empresário bemsucedido: um novo conceito em empreendedorismo, inspirado no filme Beleza Americana. RAM. Revista de Administração Mackenzie, 9(8), 112-134. Retrieved from http://www.redalyc.org/pdf/1954/195416658007.pdf

Schön, D. A. (1995). The reflective practitioner: How professionals think in action. Aldershot, UK: Arena.

Shane, S., \& Venkataraman, S. (2000). The Promise of Entrepreneurship as a Field of Research. The Academy of Management Review, 25(1), 217-226. https://doi.org/10.2307/259271

Shook, C. L., Priem, R. L., \& McGee, J. E. (2003). Venture creation and the enterprising individual: $\mathrm{A}$ review and synthesis. Journal of management, 29(3), 379-399. https://doi.org/10.1016/S0149-2063(03)00016-3

\section{Contribuições dos Autores}

$1^{\text {a }}$ autora: conceituação (igual); curadoria de dados (igual); análise formal (igual); investigação (igual); metodologia (igual); administração de projeto (igual); escrita - rascunho original (igual); escrita - revisão e edição (igual).

$2^{\circ}$ autora: conceituaçáo (igual); curadoria de dados (igual); análise formal (igual); investigação (igual); metodologia (igual); administração de projeto (igual); escrita - rascunho original (igual); escrita - revisão e edição (igual).

\section{Verificação de Plágio}

A RAC mantém a prática de submeter todos os documentos aprovados para publicaçáo à verificação de plágio, mediante o emprego de ferramentas específicas, e.g.: iThenticate

\section{Método de Revisão por Pares}

Este conteúdo foi avaliado utilizando o processo de revisão por pares duplo-cego (double-blind peer-review). A divulgação das informaçóes dos pareceristas constantes na primeira página é feita somente após a conclusão do processo avaliativo, e com o consentimento voluntário dos respectivos pareceristas

\section{Disponibilidade dos Dados}

A RAC incentiva o compartilhamento de dados mas, por observância a ditames éticos, não demanda a divulgação de qualquer meio de identificação de sujeitos de pesquisa, preservando a privacidade dos sujeitos de pesquisa. A prática de open data é viabilizar a reproducibilidade de resultados, e assegurar a irrestrita transparência dos resultados da pesquisa publicada, sem que seja demandada a identidade de sujeitos de pesquisa. 